\title{
A Case Report of the Angiosarcoma Involving Epicranial Muscle and Fascia : Is the Occipitofrontalis Muscle Composed of Two Different Muscles?
}

\author{
Ho Kyun Kim, M.D., ${ }^{1}$ Hui Joong Lee, M.D., Ph.D. ${ }^{2}$ \\ Department of Radiology, ${ }^{1}$ Catholic University of Daegu School of Medicine, Daegu, Korea \\ Department of Radiology, ${ }^{2}$ Kyungpook National University Hospital, Daegu, Korea
}

The occipitofrontalis muscle is generally regarded as one muscle composed of two muscle bellies joined through the galea aponeurotica. However, two muscle bellies have different embryological origin, anatomical function and innervations. We report a case of angiosarcoma of the scalp in a 63-year-old man whose MR showed that the superficial fascia overlying the occipital belly becomes the temporoparietal fascia and ends at the superior end of the frontal belly. Beneath the superficial fascia, the occipital belly of the occipitofrontalis muscle becomes the galea aponeurotica and inserts into the underside of the frontal belly. The presented case report supported the concept of which the occipitofrontalis muscle appears to be composed of two anatomically different muscles.

Key Words : Angiosarcoma · Occipitofrontalis · Galea aponeurotica $\cdot$ MRI.

\section{INTRODUCTION}

The occipitofrontalis muscle is generally regarded as one muscle composed of two muscle bellies joined through the galea aponeurotica ${ }^{14)}$. According to Kushima et al. ${ }^{10)}$, however, the occipitofrontalis muscle appears to be composed of two physiologically and anatomically different muscles. The position and shape of forehead, eyebrow and, hairline are affected by either contraction of only the frontalis muscle or that of both the frontalis and occipital muscles, and are also affected by either the laterally developed type or the generally developed type of frontalis muscle. In addition, electromyography demonstrated the independent actions of the occipital and frontal bellies ${ }^{4)}$. Embryologically, the frontal belly and the temporoparietal muscle originate from the platysma faciei, are innervated by the temporal branch of the facial nerve without bony attachments. On the other hand, the occipital belly and the posterior auricular muscle embryologically originate from the platysma occipitalis, are innervated by the posterior auricular branch of the facial nerve, with attachment to the occipital bone ${ }^{6}$.

Unless certain diseases involve the scalp including epicranial muscle and galea aponeurotica, it is impossible to visualization of anatomical relationship using imaging study such as $\mathrm{CT}$ and MRI, due to their thin structure. We report a case of scalp angiosarcoma in a 63-year-old man whose MR showed structural thickening due to tumor infiltration, demonstrating the detail anatomical relationship of epicranial muscle and galea aponeurotica.

\section{CASE REPORT}

A 63-year-old man with no significant medical history presented at a local dermatology clinic with a month history of erythematous patches and excoriated crust in the scalp. Initial diagnosis was chronic ulceration related with focal infection. His symptom was not improved on 4 weeks follow-up. He referred to tertiary referral university hospital for excisional biopsy and further management. On the excisional biopsy it was diagnosed as angiosarcoma with microscopic involvement of the margins. Microscopic examination showed moderately differentiated cells with invasion through the subcutaneous fat into the skin tissue. Tumor cells were strongly positive for CD31 antibody staining (Fig. 1).

MR showed larger extent of tumor involvement of scalp than visual inspection and physical examination. MRI showed a dif-

- Received : July 21, 2014 • Revised : October 25, 2014 • Accepted : November 20, 2014

- Address for reprints : Hui Joong Lee, M.D., Ph.D.

Department of Radiology, Kyungpook National University Hospital, 130 Dongdeok-ro, Jung-gu, Daegu 41944, Korea

Tel : +82-53-420-5390, Fax : +82-53-422-2677, E-mail : leehuijoong@knu.ac.kr

- This is an Open Access article distributed under the terms of the Creative Commons Attribution Non-Commercial License (http://creativecommons.org/licenses/by-nc/3.0) which permits unrestricted non-commercial use, distribution, and reproduction in any medium, provided the original work is properly cited. 
fuse soft tissue thickening along the scalp. The lesion showed high signal intensity on T2-weighted image (T2-WI) and homogeneous enhancement on contrast enhanced T1-weighted image (T1-WI). The tumor invaded subcutaneous fat with reticular patterns and spread galea aponeurotica and epicranial muscles. MR showed that the superficial fascia overlying the occipital belly becomes the temporoparietal fascia and ends at the superior end of the frontal belly. Beneath the superficial fascia, the occipital belly of the occipitofrontalis muscle becomes the galea aponeurotica and inserts into the underside of the frontal belly (Fig. 2). PET-CT showed diffuse uptake in the scalp and faint uptake in both level VA lymph nodes (Fig. 3A, B). He performed wide excision and treated with free latissimus dorsi flap and split thickness skin graft. After wide resection and recon-
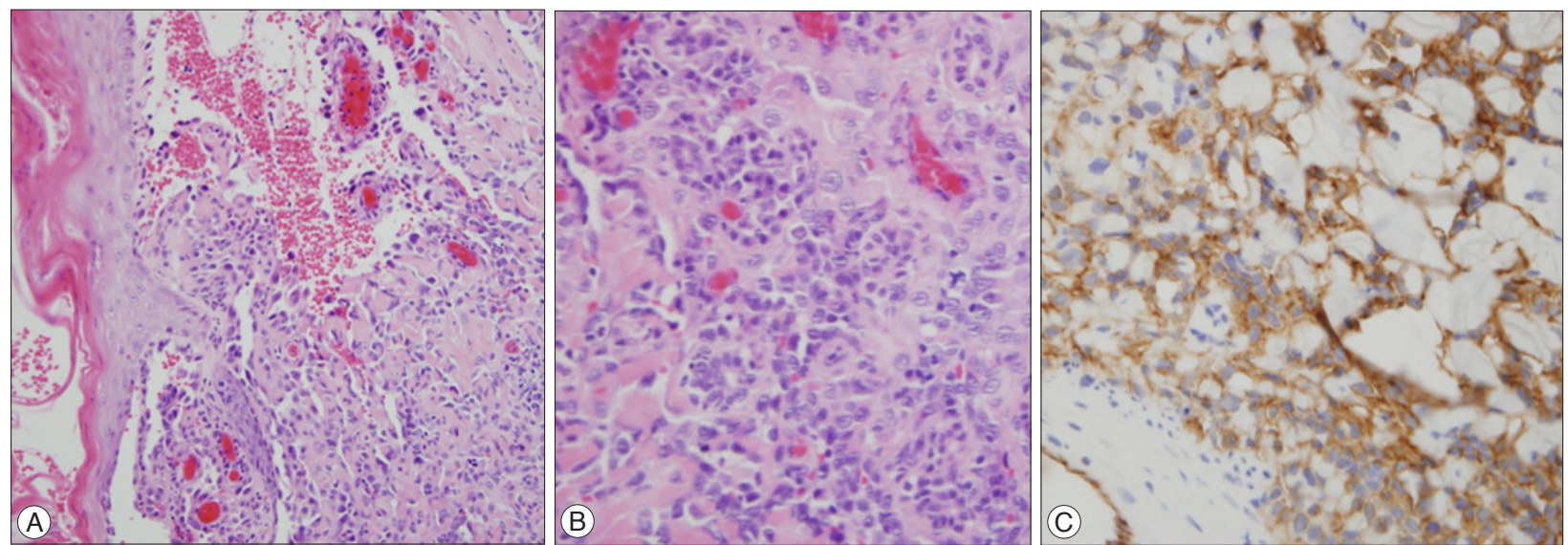

Fig. 1. 63-year-old man with angiosarcoma of the scalp. Low power $(A, \times 100)$ and high power $(B, \times 400)$. Hematoxylin-eosin stain shows pleomorphic endothelial cells, and immunohistochemical staining $(C, \times 400)$ shows positive for CD31 antibody staining.
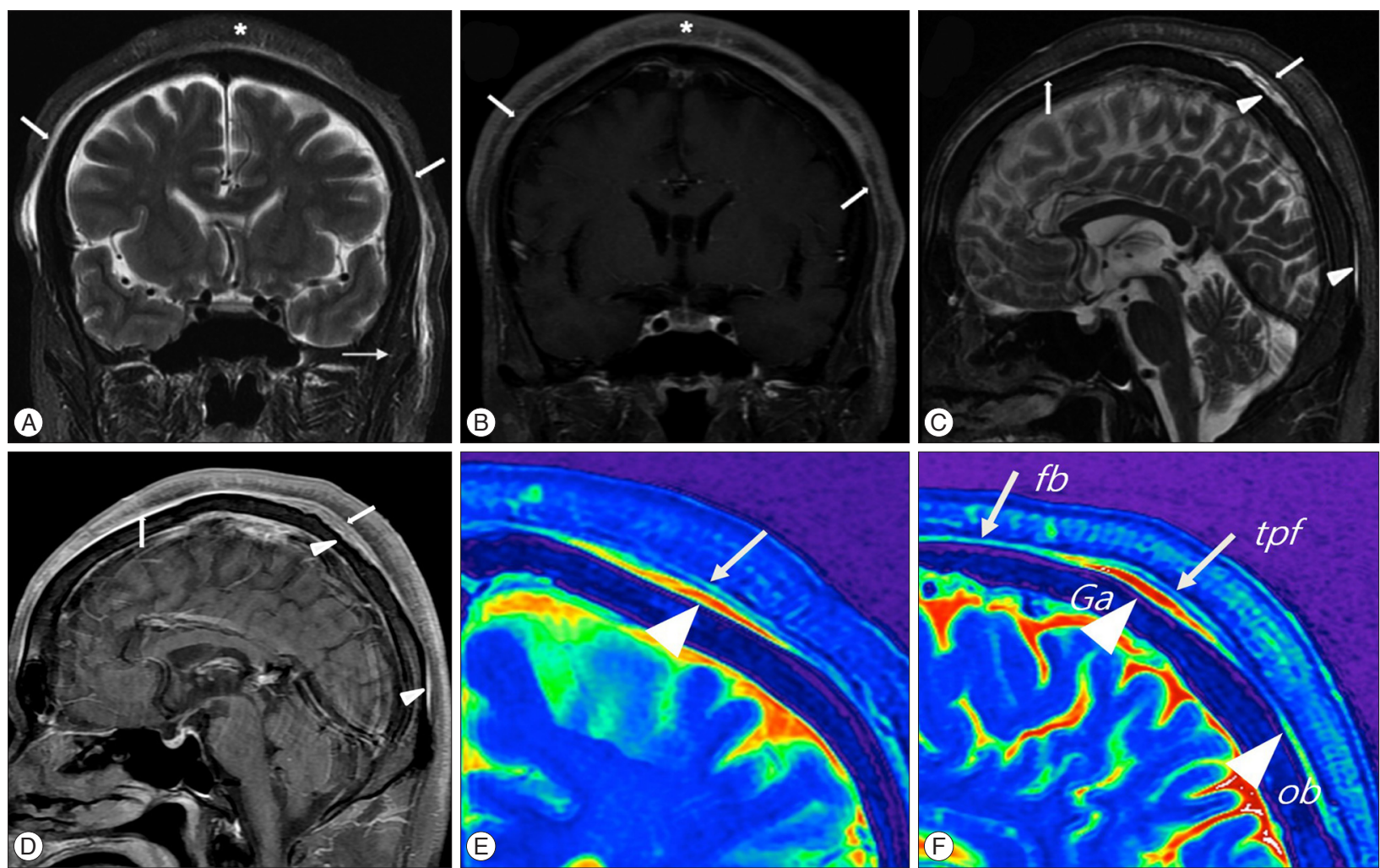

Fig. 2. Coronal view of $T 2(A)$ and contrast enhanced $T 1$ (B) weighted MR image shows a diffuse thickening of the scalp, invading subcutaneous fat with reticular patterns of high signal intensity (asterisk) due to angiosarcoma. Superficial fascia (arrows) shows diffuse thickening and enhancement, covering normal signal intensity of temporalis muscles (small arrow). Sagittal view of T2 (C) and contrast enhanced T1 (D) weighted image show tumor involvement of superficial fascia (arrows), overlying the occipital belly and galea aponeurotica (arrowheads). Color coding image according to signal intensity of coronal $(E)$ and sagittal $(F)$ views of T2 weighted MR image demonstrate the occipital belly of the occipitofrontalis muscle becomes the red colored galea aponeurotica (arrow head) and inserts into the underside of the green colored superficial musculoaponeurotic system (arrows), composed of the frontal belly of occipitofrontalis and temporoparietal fascia. Ga : galea aponeurotica, fb : frontal belly, ob : occipital belly, tpf : temporoparietal fascia. 

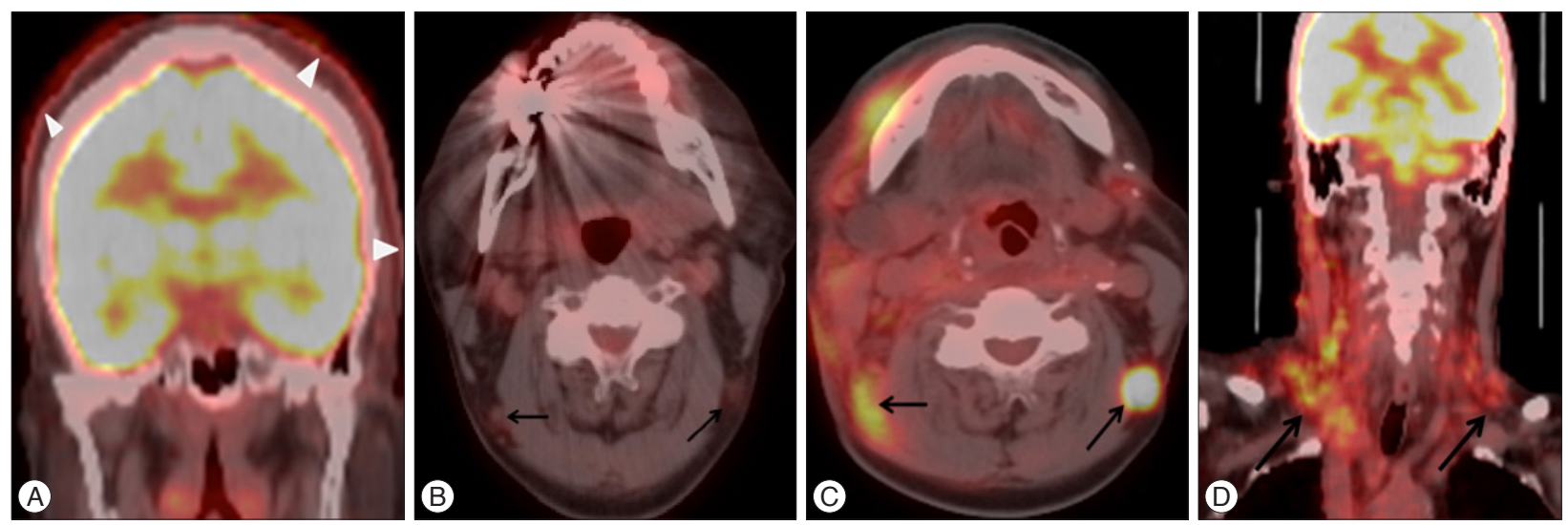

Fig. 3. PET-CT show diffuse uptake in the scalp (arrowheads) but invisible increased uptake on epicranial muscle (A). Faint uptake is visible in lymph nodes (arrows) at the level VA (B). On the 6 months follow-up PET-CT, hot uptake were visible in the level VA lymph nodes (arrow) which showed faint uptake initial study (C), and multiple lymph node metastases of both neck (arrows) are seen (D).

struction surgery, multiple lymph node metastases were detected on PET-CT (Fig. 3C, D). After radiotherapy and adjuvant chemotherapy, increased uptake lesions were disappeared.

\section{DISCUSSION}

Angiosarcoma is a rare malignant tumor of vascular endothelial cells accounting for less than $1 \%$ of all sarcomas and approximately $50 \%$ of these lesions occur in the head and neck ${ }^{2,5,11-13)}$. In contrast to the deep location of most soft tissue sarcomas, angiosarcoma has a predilection for skin and superficial soft tissue. Therefore, cutaneous angiosarcoma is the most common presentation of this neoplasm, which affects the facial skin and scalp regions. The tumor cells are located mainly in the dermis and may extend into the subcutaneous tissue, invading deep structures, such as fascia and subcutis microscopically ${ }^{12)}$. As pathologic $\mathrm{T}$ classification was a stronger indicator of long-term prognosis compared with histologic grade ${ }^{12)}$, wide surgical excision to achieve histologically tumor free margin remains the first option of the treatment. To assist in achieving negative margins, preoperative MRI can help guide the extent of the resection. MRI was useful imaging modality to demonstrate tumor invasion into the subcutaneous fat, galea aponeurotica, and skull ${ }^{9)}$. Tumor invasion into subcutaneous fat and skull was clearly visible on precontrast T1-WI. T2-WI with the fat saturation technique and especially postcontrast T1-WI with the fat saturation technique were sufficient to visualize the whole extent of angiosarcoma of the scalp.

Metastasis to regional lymph nodes or lungs can occur ${ }^{16)}$. In this case PET-CT showed diffuse uptake in the scalp and faint uptake in both level VA lymph nodes, which resulted in hot uptake on follow up PET-CT. F-18 fluorodeoxyglucose is a metabolic tracer and accumulate in soft tissue sarcoma ${ }^{3)}$. PET-CT could be not only useful in showing the whole extent of the tumor and but also sensitive to detect lymph node metastasis ${ }^{15}$. Generally surgery often is not feasible because of the multifocal nature and extensive microscopic spread pattern of these tumors. Therefore, postoperative radiotherapy and adjuvant che- motherapy are mandatory to treat patients with scalp angiosarcoma. PET-CT can be helpful to detect and follow up lymph node metastasis and local recurrence.

An understanding of the anatomy of the layers of the scalp helps to interpret the disease extent and various pathologic processes. The muscles of the calvaria including occipitofrontalis, temporoparietalis, and auricularis that arise from the galea aponeurotica are known collectively as the epicranial muscle ${ }^{1,8)}$. Because the epicranial muscle terminate directly in the subcutaneous fat, and the superficial body fascia is absent in the head and face, angiosarcoma originated from dermis, invade along the epicranial muscles and galea aponeurotica. Skull and temporalis muscles are spared relatively, because outer periosteum of skull and aponeurosis of temporalis prevent tumor invasion into deep structures. In this case, MR gave comprehensive understating for fascia anatomy of scalp, which could give information of topological anatomy to surgeon when dissecting in this region.

In this presented case report, the frontal belly of occipitofrontalis continued the temporoparietal muscle and fascia and these structures are formed into a superficial musculoaponeurotic system. The occipital belly changes into the galea aponeurotica, which inserts onto the underside of superficial musculoaponeurotic system. The commonly held concept is that the galea aponeurotica include the temporoparietal fascia, because both the temporoparietal fascia and the galea aponeurotica connect the occipital belly with the frontal belly. However, the occipital belly and the galea aponeurotica may thus create a deep musculoaponeurotic system anchored to the occipital bone, which may facilitate retraction of the superficial musculoaponeurotic system. Therefore, the galea aponeurotica should be considered to be distinct from the temporoparietal fascia as a part of a superficial musculoaponeurotic system, because the galea aponeurotica has been defined as an aponeurosis not overlying but interposing between the occipital and frontal bellies. Gola ${ }^{7}$ suggested the existence of the concept of the forehead cutaneomusculoaponeurotic unit instead of occipitofrontalis muscle, because the galea aponeurotica receives the occipitalis muscle at its deep 
surface and the frontalis muscle at its superficial surface. Our presented case showed thickened occipital belly and galea aponeurotica due to tumor cell infiltration attach the beneath of superficial fascia composed up of the frontal belly and temporoparietal fascia.

\section{CONCLUSION}

The presented case report supported the concept of which the occipitofrontalis muscle appears to be composed of two anatomically different muscles. As far as we know, this is the first case report, demonstrating the detail anatomy of epicranial muscle and galea aponeurotica.

\section{- Acknowledgements}

This research was supported by Basic Science Research Program through the National Research Foundation of Korea (NRF) funded by the Ministry of Education (No. NRF-2012R1A1A4A01005117).

\section{References}

1. Abul-Hassan HS, von Drasek Ascher G, Acland RD : Surgical anatomy and blood supply of the fascial layers of the temporal region. Plast Reconstr Surg 77 : 17-28, 1986

2. Aust MR, Olsen KD, Lewis JE, Nascimento AG, Meland NB, Foote RL, et al. : Angiosarcomas of the head and neck : clinical and pathologic characteristics. Ann Otol Rhinol Laryngol 106 : 943-951, 1997

3. Bastiaannet E, Groen H, Jager PL, Cobben DC, van der Graaf WT, Vaalburg W, et al. : The value of FDG-PET in the detection, grading and response to therapy of soft tissue and bone sarcomas; a systematic review and meta-analysis. Cancer Treat Rev 30 : 83-101, 2004

4. Bérzin F : Occipitofrontalis muscle : functional analysis revealed by electromyography. Electromyogr Clin Neurophysiol 29: 355-358, 1989

5. Figueiredo MT, Marques LA, Campos-Filho N : Soft-tissue sarcomas of the head and neck in adults and children : experience at a single institution with a review of literature. Int J Cancer $41: 198-200,1988$

6. Futamura R : Über die entwickelung der fasialismuskulatur des Menschen. Anat Hefte 30 : 436-516, 1906

7. Gola R: [The forehead cutaneo-musculo-aponeurotic unit and aging of the forehead. Anatomo-physiological considerations and surgical implications]. Ann Chir Plast Esthet 44 : 89-102, 1999

8. Hayman LA, Shukla V, Ly C, Taber KH : Clinical and imaging anatomy of the scalp. J Comput Assist Tomogr $27: 454-459,2003$

9. Isoda $H$, Imai M, Inagawa $S$, Miura K, Sakahara $H$ : Magnetic resonance imaging findings of angiosarcoma of the scalp. J Comput Assist Tomogr 29 : 858-862, 2005

10. Kushima H, Matsuo K, Yuzuriha S, Kitazawa T, Moriizumi T : The occipitofrontalis muscle is composed of two physiologically and anatomically different muscles separately affecting the positions of the eyebrow and hairline. Br J Plast Surg 58 : 681-687, 2005

11. Mark RJ, Tran LM, Sercarz J, Fu YS, Calcaterra TC, Juillard GF : Angiosarcoma of the head and neck. The UCLA experience 1955 through 1990. Arch Otolaryngol Head Neck Surg 119 : 973-978, 1993

12. Pawlik TM, Paulino AF, McGinn CJ, Baker LH, Cohen DS, Morris JS, et al. : Cutaneous angiosarcoma of the scalp : a multidisciplinary approach. Cancer 98 : 1716-1726, 2003

13. Rosai J, Sumner HW, Kostianovsky M, Perez-Mesa C : Angiosarcoma of the skin. A clinicopathologic and fine structural study. Hum Pathol 7 : 83-109, 1976

14. Standring S : Gray's anatomy. London : Churchill Livingstone, 2004

15. Vasanawala MS, Wang Y, Quon A, Gambhir SS : F-18 fluorodeoxyglucose PET/CT as an imaging tool for staging and restaging cutaneous angiosarcoma of the scalp. Clin Nucl Med 31 : 534-537, 2006

16. Wollina U, Füller J, Graefe T, Kaatz M, Lopatta E : Angiosarcoma of the scalp : treatment with liposomal doxorubicin and radiotherapy. J Cancer Res Clin Oncol 127 : 396-399, 2001 